\title{
Improved Characterization of Forest Transmissivity Within the L-MEB Model Using Multisensor SAR Data
}

\section{Seppänen, Jaakko}

2017

Seppänen , J , Antropov , O , Jagdhuber , T , Hallikainen , M , Heiskanen , J \& Praks , J 2017 , ' Improved Characterization of Forest Transmissivity Within the L-MEB Model Using Multisensor SAR Data ' , IEEE Geoscience and Remote Sensing Letters , vol. 14 , no. 8 , pp. 1408 - 1412 . https://doi.org/10.1109/LGRS.2017.2715801

http://hdl.handle.net/10138/307223

https://doi.org/10.1109/LGRS.2017.2715801

cc_by

submittedVersion

Downloaded from Helda, University of Helsinki institutional repository.

This is an electronic reprint of the original article.

This reprint may differ from the original in pagination and typographic detail.

Please cite the original version. 


\title{
Improved characterization of forest transmissivity within the L-MEB model using multi-sensor SAR data
}

\author{
Jaakko Seppänen, Oleg Antropov, Member, IEEE, Thomas Jagdhuber, Member, IEEE, \\ Martti Hallikainen, Life Fellow, IEEE, Janne Heiskanen, Jaan Praks Member, IEEE
}

\begin{abstract}
This paper proposes a novel way to assimilate SAR data to L-band microwave emission model (L-MEB) to enhance model performance over forested areas. $L$ - and $C$-band satellite SAR data are used in order to characterize the forest transmissivity within the emission model, instead of the optical satellite imagery based leaf area index (LAI) parameter.

Examination of several combinations of satellite SAR data as a substitute for LAI within the L-MEB model showed, that when ALOS PALSAR (L-band) and multi-temporal composite Sentinel-1 (C-band) data are applied, an improved agreement was achieved between the measured and simulated brightness temperatures over forests. The RMSD between modelled and measured brightness temperatures was reduced from $6.1 \mathrm{~K}$ to 4.7 K with single PALSAR scene based transmissivity correction and down to $4.1 \mathrm{~K}$ with multi-temporal Sentinel-1 composite based transmissivity correction. Suitability of single Sentinel-1 scenes varied based on seasonal and weather conditions. Overall, this indicates the potential of a SAR-based estimation of forest volume transmissivity and opens a possible way of fruitful activepassive microwave satellite data integration.
\end{abstract}

\section{INTRODUCTION}

The Soil Moisture and Ocean Salinity (SMOS) mission, launched by the European Space Agency (ESA) in 2010, has significantly improved soil moisture (SM) estimation from space at global scales [1]. Current estimation algorithms work most accurately over large and relatively dry open areas where sufficient accuracy for hydrological applications is achieved [2]. However, over forested areas the typical accuracies are distinctively lower, presumably due to more complicated temperature and moisture regimes as well as complex scattering and emission effects in forests [3]. At L-band, the tree trunks and branches contribute significantly to microwave emission and cause attenuation and scattering of soil signal [4]. A better description of these effects within the emission models can potentially improve the SM retrieval accuracy over forested regions. Such improvement can affect more than one third of the Earth's land surface area [5].

The manuscript was submitted 9.2.2017, revised 5.5.2017. The study was performed in Aalto University, Finland...

J. Seppänen, O. Antropov, M. Hallikainen and J. Praks are with the Department of Electronics and Nanoengineering, Aalto University, Finland e-mail: jaakko.seppanen@aalto.fi (see http://radio.aalto.fi).

T. Jagdhuber is with Microwaves and Radar Institute, German Aerospace Center (DLR), Münchener Strasse 20, 82234 Wessling, Germany, email: thomas.jagdhuber@dlr.de.

Janne Heiskanen is with Department of Geography, University of Helsinki, Helsinki, Finland.
The current global SM retrieval algorithm for SMOS utilizes the L-band Microwave Emission of the Biosphere (L-MEB) model to estimate the surface brightness temperature (TB), necessary for global SM retrieval [1]. In the model, the effect of the vegetation layer is taken into account by using optical remote sensing-based vegetation indices and the algorithms work well for short and sparse vegetation (non-forested areas). However, the accuracy of the SM retrieval for denser vegetation, such as forest canopy, is significantly reduced [3], [6], [7].

In the L-MEB algorithm the vegetation volume is described by several geometrical and biophysical inputs which are related to two key parameters: $L A I_{F \max }$ (maximum yearly value of arboreous LAI) and $L A I_{V}$ (LAI due to herbaceous vegetation). While the LAI describes small vegetation emission properties well, its use in case of forest might be suboptimal. In forest, the main effect on microwave attenuation (and emission) comes from larger structures, such as branches and trunks, whereas the LAI is calibrated to represent leaves, which are mostly transparent at L-band [8]. It is shown, that the LAI approach works with sparse forest where the transmissivity is in the range of $0.4-0.5$, but fails in denser forest areas (e.g., [9]-[12]). Therefore, the modelling results for emitted radiation from forests can be improved by taking better into account the stem structure of the forest.

In this study, we propose to use a SAR-based metric for characterizing the forest volume within the L-MEB emission model. The rationale behind this approach is due to routine use of satellite SAR for forest assessment, especially in the boreal forest region with relatively low biomass [13]-[17]. This can potentially lead to improved SM retrieval performance as the model is part of the SM inversion algorithm of SMOS [6].

Here we examine several possible options for integrating SAR-based description into emission models and demonstrate that better soil moisture estimates can be achieved in the case of boreal forest. The demonstration is based on ground measurements and airborne radiometer measurements performed with HUT-2D instrument over the test site in southern Finland.

Further in Section II we describe the experimental data used in this study. Section III presents the suggested modification of the L-MEB based approach incorporating satellite SAR data. In section IV, the experimental results are presented, followed by discussing and concluding the paper with future potential and research directions in Section V. 


\section{EXPERIMENTAL DATA}

In this study, experimental data were gathered from airborne radiometer measurements, satellite SAR imagery and in situ measurements of the soil.

\section{A. Test site}

The data were collected from a test site located in Rajamäki, Finland, with centre coordinates $\left(60.5760^{\circ} \mathrm{N}, 24.7730^{\circ} \mathrm{E}\right)$. The area is covered mostly by forests and agricultural fields but contains also wetlands, small lakes, urban, and industry. The land use in the study area is shown in Figure 1.

The measurements are performed over two pine-dominated coniferous forest test sites around Rajamäki. The sites have rectangular shape of about $1.5 \mathrm{~km}$ length and $800 \mathrm{~m}$ width, matching the swath of the airborne interferometric radiometer HUT-2D from $800 \mathrm{~m}$ measurement altitude (see black boxes in Fig.1).

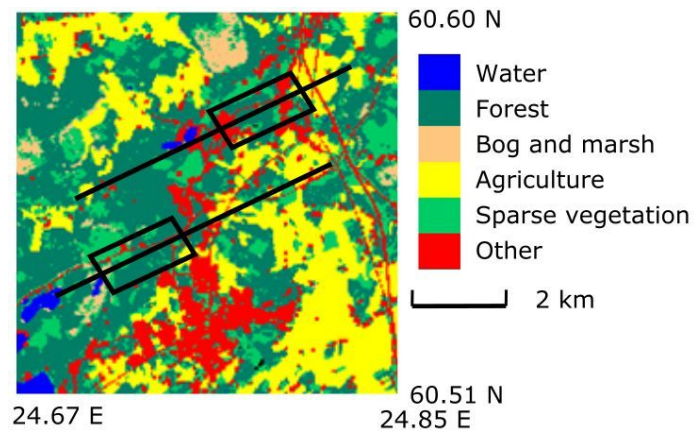

Fig. 1. Location of the test site along with measurements and reference data; lines the flight tracks used in the measurement campaign, and boxes indicate the forest areas used for analysis in this paper. Coordinates are in WGS84.

\section{B. Radiometer Data}

The airborne radiometer measurements were collected during eight flights between 2011 and 2013 by the L-band 2dimensional synthetic aperture radiometer HUT-2D [18].

The HUT-2D radiometer has 36 dual-polarimetric receivers in U-shape formation, operating at $1.4 \mathrm{GHz}$ (same as the MIRAS sensor of SMOS). In level flight the radiometer looks directly to nadir, and has a swath approximately similar to its flight altitude. It measures in the incidence angle range of $\pm 30^{\circ}$ in level flight, where each pixel is measured at several incidence angles and polarizations, depending on aircraft pitch and roll. At $800 \mathrm{~m}$ altitude its surface resolution is $80 \mathrm{~m} \times 80 \mathrm{~m}$. Radiometric resolution of the HUT-2D in the case of a typical land scene measurement, according to theory [19], yields to a resolution of $7 \mathrm{~K}$ in boresight direction and $8 \mathrm{~K}$ at 25 degrees off boresight for an individual measurement.

\section{SAR Data}

L-band SAR data is available from JAXA's ALOS PALSAR mosaic of year 2010. The data were acquired over the test site in stripmap dual-polarmetric $(\mathrm{HH}, \mathrm{HV})$ mode and pre-processed by JAXA including radiometric correction and azimuthal slope correction [20], with $25 \mathrm{~m} \times 25 \mathrm{~m}$ spatial resolution.
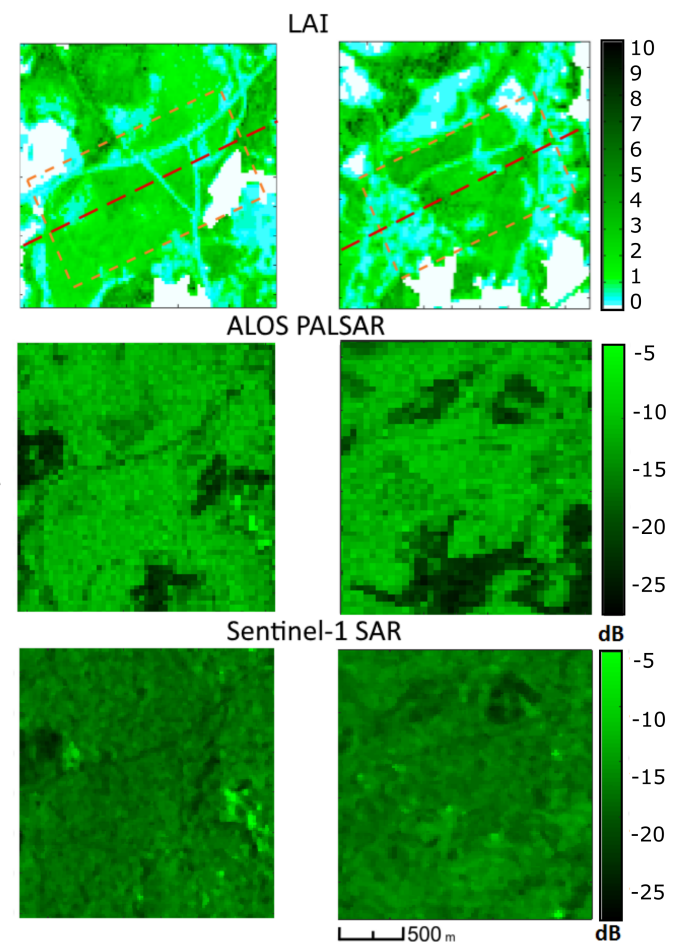

Fig. 2. LAI maps of both test sites around Rajamäki together with ALOS PALSAR and Sentinel-1 composite data.

C-band SAR data are represented by a time series of Sentinel-1 dual-polarimetric scenes (VV, VH) acquired between November 2014 and November 2015 with 24 days interval, in order to cover different seasonal and weather conditions. The images were orthorectified and radiometrically corrected using the local DEM available from National Land Survey to the same resolution of $25 \mathrm{~m} \times 25 \mathrm{~m}$.

\section{Ground Measurements}

Ground data were collected simultaneously with each overflight in order to minimize effects of temporal variation of the surface parameters. Measurements were collected for SM, organic layer thickness, and air and vegetation temperature.

The dielectric constant (water content) of the soil was measured with capacitive SM probes, so-called ThetaProbes from Delta-T [21]. SM was measured from the soil layer nearest to the surface.

In order to determine the total biomass and water content, samples of the humus layer were collected at 40 surface points. The composition of this layer varied from thin layer of litter to a layer of peat with several centimeters (mean: $4 \mathrm{~cm}$ ) formed by a decomposed moss layer. A total of 400 measurement points (of which 160 samples of soil and vegetation) were collected during the eight HUT-2D flights.

\section{E. LAI data}

The LAI 2006 database collected by Helsinki University was used as reference in calculating forest emissivity [22]. The LAI 2006 has spatial resolution of 25 meters and is based 
on Landsat 7 ETM+ and SPOT-4 satellite imagery forming a reduced simple ratio vegetation index [23]. Figure 2 shows the LAI maps of the test sites.

\section{METHODS}

The ground measurements and SAR data are used as an input for the L-MEB model in order to calculate the TBs of the test area. The simulated TBs are further compared to TBs measured by the airborne radiometer. Results from an earlier experiment [22] employing LAI data are used as a reference.

\section{A. Introduction to the $L-M E B$ biosphere emission model}

The L-band L-MEB model [24] is used as a forward model in the SMOS SM algorithm [1]. The algorithm calculates a set of TBs, taking into account the environmental parameters (such as vegetation properties) for each node, and radiometer system parameters (such as incidence angle and polarisation) for each acquisition, and then solves for the most probable moisture condition and vegetation optical depth by minimising a cost function. The basis of the model is the so called $\tau-\omega$ model pioneered by Mo et al. [25]. It is essentially the zeroth order solution of the radiative transfer equation (RTE) [24]:

$$
T_{B}=(1-\omega)(1-\gamma)\left(1+\gamma r_{g p}\right) T_{c}+\left(1-r_{g p}\right) \gamma T_{g},
$$

which calculates the total brightness temperature $T_{B}$ of each pixel in the scene, taking into account surface reflectivity $r_{g p}$ and temperature $T_{g}$, as well as vegetation effects by canopy temperature $T_{c}$, vegetation transmissivity $\gamma$ and scattering albedo $\omega[1]$. The vegetation transmissivity is

$$
\gamma=e^{-\tau / \cos \theta}
$$

where $\theta$ is incidence angle and $\tau$ is the total nadir optical depth of the vegetation, typically calculated using LAI [1]:

$$
\tau_{p}=b_{F}^{\prime} \times L A I_{F, M A X}+b_{V} \times L A I_{V},
$$

where $L A I_{F, M A X}$ is the LAI value of arboreous components in maximum development and $L A I_{V}$ is the time dependent contribution of low vegetation understory. $b_{F}^{\prime}$ and $b_{V}$ are their respective experimental coefficients. Value from [26] was used for $b_{F}^{\prime}$, and, as respective LAI covers all vegetation, the second term of (3) was set to zero.

The primary contributing layers to the $T_{B}$ over forest are soil, humus/litter layer and forest canopy [1]. The litter/humus was modelled as a continuous layer overlying the soil [1], [26]. The total reflectivity of the soil and litter ensemble with a flat surface was calculated using equations [22] for incoherent reflectivity of a two-layer surface from [27, pp. 237].

\section{B. SAR backscatter connection to forest parameters}

Estimation of forest above ground biomass (AGB) from SAR backscatter has a long tradition [13]-[15]. Two popular ways to model the dependence of both $\mathrm{C}$ and L-band SAR data on AGB are to either use semi-empirical models [16], [17], [28] originating from the water cloud model [29], or to assume a linear relationship between $\mathrm{AGB}$ and SAR backscatter amplitude [30].

Here, we will concentrate on the latter approach to avoid non-linear model training. Such simplification is acceptable as our goal was not to estimate AGB, but rather to provide a vegetation descriptor to be used as a proxy for forest transmissivity within the L-MEB model. By designating it as Radar Biomass Index $R B I$, we will use the following expression:

$$
R B I=c \times \gamma_{\text {meas }}^{0}+d,
$$

where coefficients $c$ and $d$ are typically estimated using model fitting to reference data, and $\gamma_{\text {meas }}^{0}$ is the terrain-corrected backscatter in gamma-nought format. In connection with the orthorectification and radiometric terrain correction, the following formula was used to convert satellite digital numbers $D N_{\text {meas }}$ into gamma-nought values:

$$
\gamma_{\text {meas }}^{0}=10 \times \log _{10}\left\langle D N_{\text {meas }}^{2}\right\rangle-C F,
$$

where $C F$ is a calibration factor and \langle\rangle denotes ensemble averaging. For PALSAR, $C F$ was $-83 \mathrm{~dB}$ for the whole scene, while for Sentinel-1 scenes it was range dependent. As C-band scenes are more sensitive to weather and seasonal conditions, a multi-temporally averaged SAR composite was compiled along with individual scenes. Such approach can provide more stable results and reduce speckle.

The averaging was performed in the power domain for scenes acquired under approximately similar environmental conditions [31].

\section{Integration of SAR backscatter into the L-MEB model}

The nadir vegetation optical depth (VOD) $\tau$ (2) is used for calculation of the transmissivity $\gamma$ of the forest canopy. It can be defined as [32]:

$$
\tau=K_{e} \times h,
$$

where $K_{e}\left[m^{-1}\right]$ is the extinction coefficient and $\mathrm{h}[\mathrm{m}]$ is the vegetation height. Using the definition of vegetation scattering albedo, $\omega=K_{s} / K_{e}[-], \tau$ can be linked to the scattering coefficient of the vegetation $K_{s}$ like [33]

$$
\tau=\frac{h}{\omega} \times K_{s}
$$

Hence, the scattering within the vegetation is an input parameter to $\tau$ and opens a physically justifiable way to introduce active scattering into the passive emission (L-MEB) model. However, the assumption of SAR backscatter (and thus $R B I$ ) being representative for the multi-directional scattering behavior over forest represents a considerable simplification [34].

Additionally, $h$ and $\omega$ in (7) are spatially (as well as temporally) dynamic and not known on wider scales for forests. Hence, a simplification was introduced for a more empirical, but effective SAR data integration into $\tau$. A linear relationship was assumed to calculate parameter $a$, which is used to retrieve $\tau$ in the RTE. Accounting for the $R B I$-model of (4), an explicit relationship between nadir vegetation optical depth $\tau$ and measured SAR backscatter is given with 


$$
\tau=a \times \gamma_{\text {meas }}^{o}+b,
$$

where $a$ and $b$ are empirical parameters depending on the forest structure. To approximate $a$ and $b$, the forest scene was modelled with L-MEB, and a set of optical depth values $\tau_{H U T 2 D}$ were retrieved using non-linear least squares fitting (Levenberg Marquard algorithm) of the L-MEB modelled $T_{B}$ with the HUT-2D measured $T_{B}$. During the fitting, the radiometer data are split into two subsets - for training and validation. This is done by first arranging SM values in descending order, and then assigning each sample to respective subsets in alternating manner. Coefficients of (8) fitted using the training samples are further used in the accuracy assessment against the validation data.

\section{EXPERIMENTAL RESULTS}

Experimental assessment of the proposed forest transmissivity approximation was done by comparing the HUT-2D $T_{B}$-measurements with the model-simulated $T_{B}$-values. The simulated $T_{B}$ S for a given forest patch were calculated according to the L-MEB model, taking into account the reference data (measured SM and humus layer) and forest transmissivity described either with LAI or using the proposed SAR-based $R B I$-model.

The Sentinel-1 data takes were screened for different combinations of scenes according to seasonal and weather conditions. Summer scenes had better correlation between each other than winter scenes, where snow cover on ground and on trees possibly caused higher variability. After calculating pair-wise correlations between Sentinel-1 scenes, a total of 10 images with cross-correlations over 0.6 were selected for producing the final multi-temporal composite. All these scenes were acquired during summer months, with no rain during or shortly before the image acquisition.

Both PALSAR mosaic and Sentinel-1 composite data were used with different polarizations $(\mathrm{VV}, \mathrm{VH})$ and their combination (the sum of $\mathrm{VV}$ and $\mathrm{VH}$ ) to calculate the forest transmissivity. Table I shows the calibrated coefficients and root mean squared difference (RMSD) between different L-MEB simulations of $T_{B}$ and airborne HUT-2D $T_{B}$ measurements. Accuracies provided by individual $\mathrm{C}$-band scenes varied from 4.2-5.1 $\mathrm{K}$ for summer data takes and 4.3-8.9 $\mathrm{K}$ during winter. The latter estimate is even worse than LAI-based approach. It indicates that while performance of Sentinel-1 scenes can vary, the multitemporal summer composite and the PALSAR scene represent more robust input to the L-MEB simulations.

Figure 3 shows the comparison of selected $T_{B}$ L-MEB simulations against HUT-2D-measured $T_{B}$ levels for different input data - LAI map (left), ALOS PALSAR HV-pol (centre) and Sentinel-1 VV-pol composite (right). Further analysis has revealed that practically all SAR-based inputs into the $\tau$ (VOD) and transmissivity equations (cf. (2) to (9)) improved over the LAI-based $T_{B}$ simulations.

\section{Discussion AND CONCLUSIONS}

Use of SAR backscatter instead of LAI has revealed a considerable improvement in the forest transmissivity calculation via comparison between sets of experimentally measured
TABLE I

ACCURACY AND CORRELATION OF L-MEB-SIMULATED $T_{B}$ VS HUT-2D-MEASURED $T_{B}$ FOR DIFFERENT SAR BACKSCATTER POLARIZATIONS AND THEIR COMBINATION

\begin{tabular}{|l|l|l|l|}
\hline \multirow{2}{*}{} & \multicolumn{2}{|l|}{ Coefficients } & $\begin{array}{l}\text { Simulated vs. } \\
\text { measured } T_{B}\end{array}$ \\
\cline { 2 - 4 } & $b_{F}^{\prime}$ & $\begin{array}{l}b_{V} \cdot \\
L A I_{V}\end{array}$ & RMSD, K \\
\hline Leaf area index (LAI) & 0.36 & 0 & 6.1 \\
\hline & $a$ & $b$ & \\
\hline PALSAR HH & 1.9 & 0.36 & 4.7 \\
\hline PALSAR HV & 6.1 & 0.32 & 4.7 \\
\hline PALSAR HH+HV & 1.7 & 0.29 & 4.9 \\
\hline Sentinel-1 VV, multi-temp & 10.8 & 0.18 & 4.2 \\
\hline Sentinel-1 VH, multi-temp & 4.3 & 0.13 & 4.3 \\
\hline Sentinel-1 VV+VH, multi-temp & 2.7 & 0.19 & 4.1 \\
\hline
\end{tabular}

and modelled $T_{B}$. Though the scale of measurements was relatively limited, it clearly indicates suitability of a SARbased $R B I$-model approach in calculating $\tau$ (VOD), and transmissivity respectively, as part of a specialized L-MEB model for forested environments.

Interestingly, the performance of estimates provided by multi-temporal Sentinel-1 summer composite and the ALOS PALSAR scene were practically the same, indicating that either of these can be potentially used in an operational scenario. Performance of individual Sentinel-1 scenes varied strongly, with better consistent accuracies provided by scenes acquired in summer. It is important to note the low dependence of polarisation on the prediction performance. This might indicate that even at L-band the contribution of the ground floor (e.g. double-bounce mechanism) was relatively minor and most of scattering was from the canopy. This is in agreement with several other studies [13], [17], [28], [35] attributing this effect to relatively hilly terrain and strong attenuation of SAR backscatter in the understory layers and forest floor. It is also important to keep in mind that the $T_{B}$ measurement accuracy is limited by the sensitivity of the HUT-2D sensor.

Overall, in the light of other operating and planned SAR missions, this study suggests that their data can be used to better understand and improve the accuracy of radiometerbased soil moisture estimation, particularly over forested areas. Polarisation dependence, as well as optimal conditions for Lband image acquisition and multitemporal L-band composite, will be investigated in future research, along with actual soil moisture estimation using suggested approach.

\section{REFERENCES}

[1] Y. Kerr, P. Waldteufel, P. Richaume, J. Wigneron, P. Ferrazzoli, A. Mahmoodi, A. Al Bitar, F. Cabot, C. Gruhier, S. Juglea, D. Leroux, A. Mialon, and S. Delwart, "The SMOS soil moisture retrieval algorithm," IEEE Trans. Geosci. Remote Sens., vol. 50, no. 5, pp. 1384-1403, May 2012.

[2] Y. Kerr, A. Al-Yaari, N. Rodriguez-Fernandez, M. Parrens, B. Molero, D. Leroux, S. Bircher, A. Mahmoodi, A. Mialon, P. Richaume, S. Delwart, A. A. Bitar, T. Pellarin, R. Bindlish, T. Jackson, C. Rüdiger, P. Waldteufel, S. Mecklenburg, and J.-P. Wigneron, "Overview of SMOS performance in terms of global soil moisture monitoring after six years in operation," Remote Sens. Env., vol. 180, pp. 40-63, 2016.

[3] R. Rahmoune, P. Ferrazzoli, Y. H. Kerr, and P. Richaume, "SMOS level 2 retrieval algorithm over forests: Description and generation of global maps," IEEE Journal of Selected Topics in Applied Earth Observations and Remote Sensing, vol. 6, no. 3, pp. 1430-1439, June 2013. 

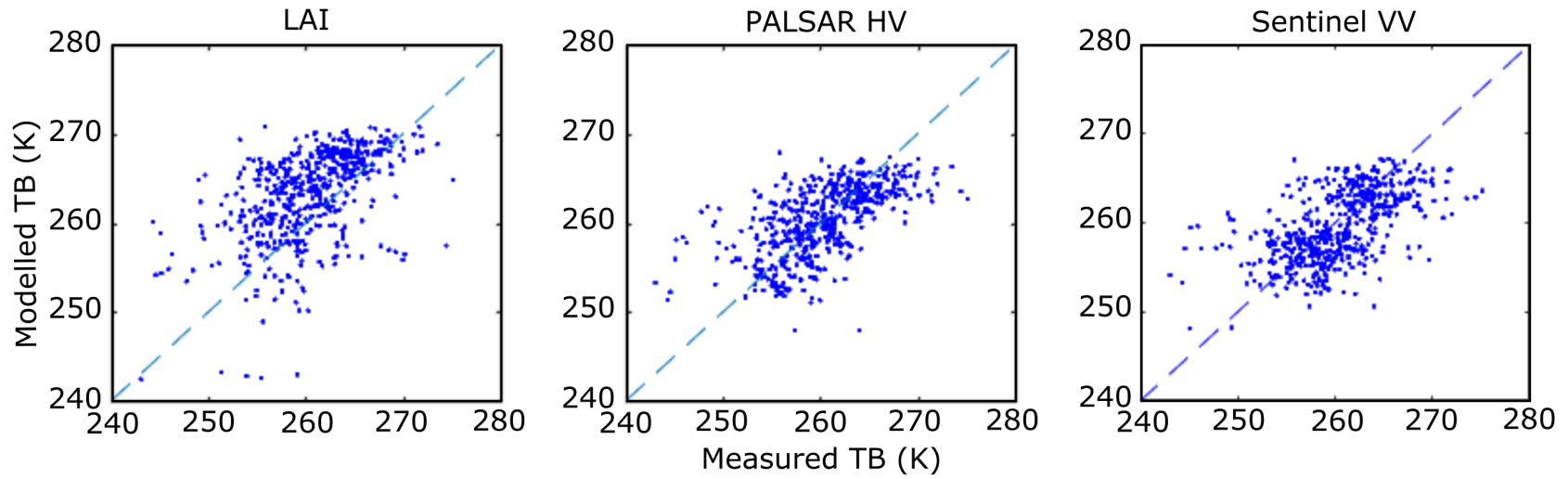

Fig. 3. Model-simulated vs HUT-2D-measured $T_{B}$ using different approaches in approximating transmissivity in the L-MEB model (left: LAI; center: PALSAR, HV-pol.; right: Sentinel-1 multi-temporal summer composite, VV-pol.).

[4] A. Della Vecchia and P. Ferrazzoli, "A large scale approach to estimate L-band emission from forest covered surfaces," ESA Technical note SOTN-TV-GS-0001-01.a, Feb 2006.

[5] Global Forest Resources Assessment 2015: How have the worlds forests changed? FAO, 2015.

[6] A. Van de Griend, J.-P. Wigneron, and P. Waldteufel, "Consequences of surface heterogeneity for parameter retrieval from 1.4-GHz multiangle SMOS observations," IEEE Trans. Geosci. Remote Sens., vol. 41, no. 4, pp. 803-811, April 2003.

[7] J. Seppänen, J. Kainulainen, J. Heiskanen, J. Praks, and M. T. Hallikainen, "Measurements of boreal coniferous forest soil and humus with an airborne radiometer," IEEE J. Sel. Topics Appl. Earth Obs. Remote Sens., vol. 9, no. 7, pp. 3219-3228, July 2016.

[8] P. Ferrazzoli, L. Guerriero, and J.-P. Wigneron, "Simulating L-band emission of forests in view of future satellite applications," IEEE Trans. Geosci. Remote Sens., vol. 40, no. 12, pp. 2700-2708, Dec 2002.

[9] R. Lang, C. Utku, P. de Matthaeis, N. Chauchan, and D. Le Vine, "ESTAR and model brightness temperatures over forests: Effects of soil moisture," Proc. IEEE Intl. Geosci. Remote Sens. Symp. Symposium IGARSS 2001, vol. 3, pp. 1300-1302, 2001.

[10] M. Guglielmetti, M. Schwank, C. Mätzler, C. Oberdörster, J. Vanderborght, and H. Flühler, "FOSMEX: Forest soil moisture experiments with microwave radiometry," IEEE Trans. Geosci. Remote Sens., vol. 46, no. 3, pp. 727-735, 2008 .

[11] J. P. Grant, K. Saleh, J.-P. Wigneron, M. Guglielmetti, Y. Kerr, M. Schwank, N. Skou, and A. A. Van de Griend, "Calibration of the L-MEB model over a coniferous and a deciduous forest," IEEE Trans. Geosci. Remote Sens., vol. 46, no. 3, pp. 808-818, 2008.

[12] T. Jagdhuber, I. Hajnsek, S. Sauer, K. Papathanassiou, and A. Bronstert, "Soil moisture retrieval under forest using polarimetric decomposition techniques at P-band," in Proc. EuSAR 2012, 2012, pp. 709-712.

[13] M. Dobson, F. Ulaby, T. LeToan, A. Beaudoin, E. Kasischke, and N. Christensen, "Dependence of radar backscatter on coniferous forest biomass," IEEE Trans. Geosci. Remote Sens., vol. 30, no. 2, pp. 412415, Mar 1992.

[14] M. L. Imhoff, "Radar backscatter and biomass saturation: ramifications for global biomass inventory," IEEE Trans. Geosci. Remote Sens., vol. 33, no. 2, pp. 511-518, Mar 1995 .

[15] Y. Rauste, T. Hme, J. Pulliainen, K. Heiska, and M. Hallikainen, "Radarbased forest biomass estimation," Intl. J. Remote Sens., vol. 15, no. 14, pp. 2797-2808, 1994

[16] M. Santoro, L. Eriksson, J. Askne, and C. Schmullius, "Assessment of standwise stem volume retrieval in boreal forest from JERS1 Lband SAR backscatter," Intl. J. Remote Sens., vol. 27, no. 16, pp. 3425-3454, 2006.

[17] O. Antropov, Y. Rauste, H. Ahola, and T. Hame, "Stand-level stem volume of boreal forests from spaceborne SAR imagery at L-Band," IEEE J. Sel. Topics Appl. Earth Obs. Remote Sens., vol. 6, no. 1, pp. 35-44, Feb 2013

[18] K. Rautiainen, J. Kainulainen, T. Auer, J. Pihlflyckt, J. Kettunen, and M. Hallikainen, "Helsinki University of Technology L-band airborne synthetic aperture radiometer," IEEE Trans. Geosci. Remote Sens., vol. 46, no. 3, pp. 717-726, March 2008.
[19] A. Camps, I. Corbella, J. Bara, and F. Torres, "Radiometric sensitivity computation in aperture synthesis interferometric radiometry," IEEE Trans. Geosci. Remote Sens., vol. 36, no. 2, pp. 680-685, March 1998.

[20] M. Shimada, T. Itoh, T. Motooka, M. Watanabe, T. Shiraishi, R. Thapa, and R. Lucas, "New global forest/non-forest maps from ALOS PALSAR data (2007-2010)," Remote Sens. Env., vol. 155, pp. 13-31, 2014.

[21] User Manual for the Moisture Meter type HH2. Delta-T Devices Ltd. Burwell, March 2002.

[22] J. Seppänen, J. Kainulainen, J. Heiskanen, J. Praks, and M. Hallikainen, "Measurements of boreal coniferous forest soil and humus with an airborne radiometer," IEEE J. Sel. Topics Appl. Earth Obs. Remote Sens, vol. 9, no. 7, pp. 3219-3228, July 2016.

[23] J. Heiskanen, M. Rautiainen, L. Korhonen, M. Mottus, and P. Stenberg, "Retrieval of boreal forest LAI using a forest reflectance model and empirical regressions," Intl. J. Appl. Earth Obs. Geoinformation, vol. 13, no. 4, pp. 595-606, 2011

[24] J.-P. Wigneron, Y. Kerr, P. Waldteufel, K. Saleh, M.-J. Escorihuela, P. Richaume, P. Ferrazzoli, P. de Rosnay, R. Gurney, J.-C. Calvet, J. Grant, M. Guglielmetti, B. Hornbuckle, C. Mätzler, T. Pellarin, and M. Schwank, "L-band microwave emission of the biosphere (L-MEB) model: Description and calibration against experimental data sets over crop fields," Remote Sens. Env., vol. 107, pp. 639-655, 2007.

[25] T. Mo, B. Choudhury, T. Schmugge, J. Wang, and J. T.J., "A model for microwave emission from vegetation-covered fields," Journal of Geophysical Research, vol. 87, no. C3, pp. 11 229-11 237, 1982.

[26] Y. Kerr, P. Waldteufel, P. Richaume, I. Davenport, P. Ferrazzoli, and J.-P. Wigneron, SMOS Level 2 Processor Soil Moisture ATBD, SM-ESL (CBSA), Toulouse SO-TN-ESL-SM-GS-0001, 09/12/2010, 2010.

[27] F. Ulaby, R. Moore, and A. Fung, Microwave Remote Sensing - Active and Passive. Addison-Wesley, 1981, vol. I.

[28] J. T. Pulliainen, L. Kurvonen, and M. T. Hallikainen, "Multitemporal behavior of L- and C-band SAR observations of boreal forests," IEEE Trans. Geosci. Remote Sens., vol. 37, no. 2, pp. 927-937, Mar 1999.

[29] E. P. W. Attema and F. T. Ulaby, "Vegetation modeled as a water cloud," Radio Science, vol. 13, no. 2, pp. 357-364, 1978.

[30] Y. Rauste, "Multi-temporal JERS SAR data in boreal forest biomass mapping," Remote Sens. Env., vol. 97, no. 2, pp. 263 - 275, 2005.

[31] S. Quegan and J. J. Yu, "Filtering of multichannel SAR images," IEEE Trans. Geosci. Remote Sens., vol. 39, no. 11, pp. 2373-2379, Nov 2001.

[32] A. Van De Griend and J. Wigneron, "The b-factor as a function of frequency and canopy type at h-polarization," IEEE Trans. Geosci. Remote Sens., vol. 42(4), pp. 786 - 794, 2004.

[33] J.-P. Wigneron, J.-C. Calvet, A. Chanzy, O. Grossean, and L. Laguerre, "A composite discrete-continuous approach to model the microwave emission of vegetation," IEEE Trans. Geosci. Remote Sens., vol. 33, pp. 201-211, 1995.

[34] Y. Jin, Electromagnetic scattering modelling for quantitative remote sensing. World Scientific Press, 1993.

[35] O. Antropov, Y. Rauste, and T. Häme, "Volume scattering modeling in PolSAR decompositions: Study of ALOS PALSAR data over boreal forest," IEEE Trans. Geosci. Remote Sens., vol. 49, no. 10, pp. 38383848, Oct 2011. 